\section{Ueber bakteriologische Befunde bei den Gasphlegmonen.}

\section{Bemerkungen zu dem Aufsatz von R. Pfeiffer und G. Bessau. Von L. Aschoff.}

In dem oben genannten Aufsatz (Nr. 39-41) schreiben die Verfasser (S. 1256): ,Wir treten der Ansicht Aschoffs und seiner Mitarbeiter, die einen einheitlichen Gasphlegmoncbazillus annehmen, ... init aller Entschiedenheit entgegen." Der unbefangene Leser könnte daraus schließen, daß ich nur einen bestimmten, genan umschricbonen Erreger des Gasödems kenne oder anerkenne. Das ist ein Irrtum, der dadurch nicht zur Wahrheit wird, daß er mehrfach behauptet wurde (s, a. Schottmüller). ${ }^{1}$ ) Ich bin nie so weit gegangen wie E. Fraenkel, der im Jahre 1899 im Gegensatz zu seinem ursprünglichen Standpunkt von „dem" Erreger der Gasphlegmone spricht, sondern habe nur behauptet, daß außer dem Welch - Fraenkelschen Bazillus noch andere Erreger der menschlichen, mit Gas- und Oedem. bildung einhergehenden Infektionskrankheit in Botracht kommen. ,Scheidet also der Fraenkelsche Oedembazillus ebenso wie der Welch - Fraenkelsche Gasbazillus für insere genau genug unter. suchten Fälle als Infektionserreger aus, so fragt es sich, mit welchem anderen als Erreger von Gasọdem bekannten Anaërobier er verglichen werden kann.“2) Ferner: „Jedenfalls gehört unsel" Bazillus weder zu dem Welch-Fraenkelschen Gasbazillus, noch zu dem Fraenkelschen Oedembazillus, sondern ist am nächsten dem GhonSachsschen Oedembazillus verwandt." Ich habe also im Namen meiner Mitarbeiter mit aller Schärfe das Vorkommen verschiedener Bazillen bei der Gasödemerkrankung des Menschen betont und mich gegen die noch im Anfang dieses Krieges von Fraenkel vertretene Auffassung der einheitlichen Genese gewandt. Die Bəfunde von Pfeiffer und Bessau bestätigen nur unsere Angaben. Die von F. Klose an unserem und seinem Material durchgeführten serologischen und agglutinatorischen Arbeiten haben uns eine weitere Differenzierung der gefundenen Erreger gestattet. Er hat darübsr in einer Sitzung des Senats der Kaiser-Wilholms-Akademie im April d. J. eingehender berichtet. ${ }^{3}$

Wenn wir somit von Anfang an für die Vielheit der Gasodem. erreger eingetreten sind, so haben wir umgekchrt die schwierige. Abgrenzung der einzelnen Arten nach den bis dahin angewandten und angegebenen Methoden besonders für die Rauschbrand- und dis maligne Oedemgruppe hervorgehoben und betont, daß es von dem Welch Fraenkelschen Bazillus angefangen bis zum malignen 0edcmbazillus zahlreiche Zwischenformen gibt, sodaß für die Gasödemerkrankungon, ähnlich wie für die Dysenterie- und die Typhuserkrankungen, zumal bei den fließenden Uebergängen der klinischen Bilder, die ganze Erkrankungsform als eine mehr einheitlich bedingte, nur verschiedeno Variationen aufweisende aufzufassen ist. Wir stellten uns damit ganz auf den ursprünglichen Standpunkt von Fraenkel, welcher für die A stiologie der Gasgangrän folgenden Satz aufstellte: „Soweit das. bishər vorliegende tatsächliche Material ein definitives Urteil gestattet, handelt es sich dabii um Bazillen, die, einander verwand t, zi den Bazillen dos malignen Oedems, dem Pseudoödem. und Rauschbrandbazillus in nah»r Beziehung stehen." Wàs uns von Fraenkel trennt, war nur dic Auffassung übər die prozentuale Beteiligung der verschiedenen Err`ger am menschlichen Gasödem. Während Fraønkel glaubt, daß der Welch-Fraenkelsche Bazillus in fast allen Füllen von menschlichom Gasbrand als alleiniger Erreger in Betracht komme, konnten wir uns davon überzeugen, daß in der Mehrzahl der Fälle, ja in gewissen Kampfzonen ausschließlich, die beweglichen Formen d. h. alro Erreger aus der Gruppe des malignen Oedems und des Rauschbrands, in Betracht kommen. Wenn in diesem Punkte die Meinungen noch auseinandergehen, so zeigen doch die Untersuchingen von Pfeiffer und Bessau, daß auch sie in einem gegen frühere Annahmen iiberraschend hohen Prozentsatz andere Erreger als den Welch. Fraenkelschen Bazillus gefunden haben.

Eine andere von Pfeiffer und Bessau bəührte Frage, nämlich die der Umwandlungsmöglichkeiten oder der Uebergänge zwischen den verschiedenen Erregergrupp»n, haben wir ganz offengelassen. Solche Möglichkeiten lassen sich unseres Erachtens nach zurzcit weder beweisen, noch völlig ablehnen. Dazu reicht unsere wissenschaftlich Erkenntnis noch nicht aus.

Schließlich behaupten die Verfasser die Identität ihres Uhrzeigerbazillus mit unserem (in Kolmar) gezüchteten Bazillus. Da über die

1) Ich kann hier nur für diejenigen Veröffentlichungen eintreten, in denen ich selbst zu dieser Frage Stellung genommen habe.

2) D. m. W. 1916 S. 513.

3) Siehe das demnächst erscheinende Heft der Vöff. Milit.Sar.tatsw.
Tierversuche noch nicht eingehender werichtet ist, lassen sich diese allerdings nicht vergleichen. Aber die Angabs, daß ihr Uhrzeigerbazillus wenig pathogen gewesen ist, steht in scharfem Gegensatz zu unseren Befunden. Gerade unser Bazillus erwies sich als sehr pathogen für Meerschweinchen, Ratte, Maus, Kaninchen, selbst fïr Pferd und Rind. Auch war unser Bazillus Gram-labil, besonders in älteren Kulturen. Ich verweise diesbezüglich auf die Ausführungen von Ernst Fraenkel, Koenigsfeld. und Frankenthal. ${ }^{1}$ ) Auch schwärzt der Kolmarer Bazillus den Gehirnnährboden wicht, verwandelt ihn auch nicht in cine schwarzgrünliche, stinkende Masso. Vielmehr ist das Oedem beim Tiere geruchlos, der Geruch der Kulturen auf Zuckernährböden säuerlich, sonst fade (fäulnisartiger Geruch), aber kein Gestank. Unser (Kolmarer) Bazillus ist also kein Fäulniserreger im Sinne Pfeiffer's und Bessaus. Vielmehr glaube ich allen Grund zu der Annahme zu haben, daß der als Bazillus des malignen Oedems von den Verfassern beschriebene Gasödemerreger mit unserem Kolmarer Bazillus zu vergleichen ist. Sehen wir von den Kulturen in Agar ab, die von der Zusammensetzung des Agars beeinflußt sein können, so lassen sich für beide Bazillen ähnliche Merkmale, von der geringen Beweglichkeit angefangen bis zur Nichtschwärzung des Agars, nachweisen. Ich will daher auch auf die nach obigem hinfällige Schlußfolgerung von Pfeiffer und Bessau in bezug auf unsere bakterioskopischen Be. funde, die sie in folgende Worte kleiden: „Wir deuten das Ergebnis so, daß in das gesunde Gewebe die sporenlosen Fraenkel schen Bazillen vorgedrungen waren, während die sporenhaltigen Fäulnisbakterien (die Sehilderung paßt anf unsere „Uhrzeigerbazillen“) ihre Tätigkeit auf die Trümmerstätte des Primäraffektes beschränkten und hier überwucherten" nicht weiter eingehen, muß aber daran festhalten, daß man nur dann zu einer richtigen Beurteilung der Aetiologie der Gasödemerkrankungen kommt, wenn man am Lebenden oder an der Leiche, und zwar alsbald nach dem Tode, die verschiedensten erkrankten Gebicte bakterioskopisch und bakteriologisch untersucht. Das ist nur selten geschehen, von uns nach Möglichkeit versucht worden.

Wir haben unsern Bazillus dem Ghon-Sachsschen Bazillas an die Seite gestellt. Wir haben seinerzeit vorgeschlagen, diesen als den echten Kochschen Bazillus des malignen Oedems anzuerkennen. Mit diesem Vorschlag würde derjenige von Pfeiffer und Bessau durchaus im Einklang stehen. Doch haben wir in Rücksicht auf Hiblers systematische Untersuchungen uns letzthin seinem Vorgehen angeschlossen und bezeichnen daher die putrifizicrenden Arten der Gasödemerreger als Bazillen des malignen Oedèms (wie auch v. 'Baum. garten u. a.), dagegen die nicht putrifiziercnden, beweglichen Formen als Rauschbrandgruppe, wozu wir. um so mehr berechtigt sind, als diese von dem tierischen Rauschbrandserum agglutiniert werden, die putrifizierenden Gasödemerreger dagegen nicht. Da ein Originalstamm des Kochschen Bazillus des malignen Oedems nicht mehr zu existioren scheint, Kochs Angaben aber zu lückenhaft für eine Identifizierung sind, so bleibt es der Willkür oder der freien Vereinbalung iiberlassen, was man als Bazillus des malignen Oedems bezeichnen will oder nicht. Von uns ist folgende Nomenklatur vorgeschlagen worden:

Gasödemerkrankungen (Emphyso-vedema malignum) Bacilli emphyso-oedematis maligni.

\begin{tabular}{|c|c|c|}
\hline I. Gasbrandgruppe & $\begin{array}{l}\text { Ap at thogene } \\
\text { Vertreter. } \\
\text { Bac. saccharo-butyricus } \\
\text { immobilis }\end{array}$ & $\begin{array}{l}\text { Pathogene } \\
\text { Vertreter. } \\
\text { Welch-Fraenkelsche } \\
\text { Gruppe. }\end{array}$ \\
\hline & $\begin{array}{l}\text { Bac. amylobacter } \\
\text { Bac. sacch. butyric. m }\end{array}$ & $\begin{array}{l}\text { Conradi-Bielingsche } \\
\text { Gruppe. } \\
\text { Ghon-Sachssche Gruppe }\end{array}$ \\
\hline 11. Kauschoranagruppe & Bac. paraputrificus & $\begin{array}{l}\text { (Vibrion septlque } \\
\text { Pasteurs) } \\
\text { Kolmarer Gruppe. }\end{array}$ \\
\hline $\begin{array}{l}\text { III. Gruppe d. malignen } \\
\text { Oedems }\end{array}$ & Bac. putrificus & $\begin{array}{l}\text { v. Hiblers maligner } \\
\text { Oedembazillus (Kochs } \\
\text { maligner Oedembaz.? } \\
\text { Koch-Hiblersche } \\
\text { Gruppe. }\end{array}$ \\
\hline
\end{tabular}

Wir schrieben dazil:

„In ciner frïheren Arb it wusde vorgesehlagen, den Ghon-Sachsschen Bazillus wagen seiner Ueb reinstimmung mit dem Vibrion septique Pasteur's als echton malignen Oedembazillus zu bezeichnen. Nachdem sich nun h?ransgestellt hat, daß unter den menschlichen Gasödemfällen eine gewisse Zahl anch durch Erreger bedingt wird, die dem Ghon-Sachsschen Bazillus, d. h. damit auch dem Vibrion septiqne Pasteur's verwandt sind, sich abər von ihm durch dic Alkalisierung des Nährbodens und Schwärzung des Hirnbreies unterscheiden, also der Putrifikusgrilpp 3 zugerechnet, werden müssen, bleibt es wieder offen, wohin man den Kochsohen Bazillus des malignen Oedems rechnen will. Man kann ihn mit dem Hiblersch?n Bazillus des malignen

1) Med. Kl. 1916 Nr. 26 u. 27. 
Oedems identifizieren, was doch das Empfehlenswerteste sein dürfte, muß dann aber die alte Lehre aufheben, daß Vibrion septique Paste ur und Kochscher Bacillus oedematis maligni ein und dicselben Organismen sind."

Der Einwand, daß nach Koch B Beschreibung sein Bazillus keine Fäulnis hervorgerufen hat und daher ein fäulniserregender Bazillus nicht als Kochscher Bazillus des malignen Oedems bezeichnet werden darf, trifft nicht zu. Im Tierexpsriment ruft auch der Hiblersche Oedembazillus keine stinkende Zersetzung hervor, sondern im wesentlichen das Bild des leicht sanguinolenten Oedems. Ueber die Stoffwechselprodukte und über die Kulturen sagt Koch nichts. Ich möchte weiter bomerken, daß bisher von kəinor anderen Seite ein einigermaßen zutreffender, zusammenfassender Name für diese Krankheitsbilder vorgeschlagen worden ist. Die vielen verschieden gebrauchten Namen steigern nur die Verwirrung. Der Name ,ödematöses Emphysem“ ist neuerdings von Köwes für die durch den Ghon-Sachsschen Bazillus hervorgerufenen Bradsot-ähnlichen Krankheitsbilder des Schweines in Vorschlag gebracht worden. Ich' möchte an meinem Vorschlag festhalten, die ganze, klinisch durch so zahlreiche Uebergänge in sich verbundene Krankheitsgruppe als „Emphyso-oedema malignum“ oder "Gasödeme" zu bezeichnen. Jedenfalls scheint mir diese auf das klinische Bild hindeutende Bezeichnung richtiger als der vom ätiologischen Standpunkt aus geprägte, ein oft fehlendes Symptom einseitig hervorhebende und daher leicht irreführende Name „Gasbazilleninfektion", wie ihn Wieting vorgeschlagen hat.

Welchem Vorschlag man folgt, ist gleichgültig. Die Hauptaufgabe zukünftiger Forschung bleibt neben der serologischen Differenzierung diejenige nach den Stoff wechselprodukten. Darin stimmen wir mit Pfeiffer und Bessau völlig üb rrein. Erst eine genaue biologische Kenntnis der einzelnen Gasödemerreger wird uns die Herstellung eines wirklichen omnivalenten, womöglich auch antitoxischen Serums ermöglichen. Die Mitteilungen von Pf eiffer und Bessau zeigen, daß von allen bisher hergestellten Søra nur das Höchster Serum als ein im Agglutinationsversuch wirksames polyvalentes Serum bezeichnet werden darf. Ueber seine Wirksamkeit beim Menschen, die vorläufig nur prophylaktisch, noch garnicht therapeutisch erprobt ist, werden erst große Erfahrungsreihen ein Urteil gestatten. Solange wird es die Aufgabe der Serologen sein, auf Grund der fortschreitenden Erkenntnis ein im Tierversuch noch besseres Serum herzustellen. Auch in dieser Beziehung stimmen wir mit Pfeiffer und Bessau durchaus überein. 